\title{
Property price gradients: the vertical dimension
}

\author{
S. K. Wong $\cdot$ K. W. Chau $\cdot$ Y. Yau $\cdot$ A. K. C. Cheung
}

Received: 17 December 2008/Accepted: 15 November 2010/Published online: 4 December 2010

(C) The Author(s) 2010. This article is published with open access at Springerlink.com

\begin{abstract}
This is an empirical study on the pricing of two vertical property attributes: floor level and building height. Floor level is the vertical location of a unit in a multi-storey building; the extra price paid for a higher floor level is labelled a floor-level premium. Previous hedonic price studies unequivocally showed that the floor-level premium is positive, but they were silent on whether its magnitude varies with floor levels and with buildings of different heights. Indeed, building height is a feature of a building, not its constituent units, so it is not clear whether building height alone should affect the units' prices. Based on a sample of highly homogeneous housing units in buildings of varying heights, we found that (1) the floor-level premium was not constant, but diminished as floor level increases; (2) there was no significant difference in the pattern of the floor-level premium between high-rise and low-rise buildings; and (3) there was a positive and significant premium for units in low-rise buildings over those in high-rise ones. These findings can help developers determine the optimal height and shape of their development.
\end{abstract}

Keywords Housing price $\cdot$ Hedonic model $\cdot$ Floor level $\cdot$ Building height $\cdot$ Price gradient

\section{Introduction}

"Location, location, location" is a famous old saying that teaches us the importance of location in choosing and pricing property. Taken literally, location refers to the geographic position of a building. It has become a major focus in urban economics since Alonso's (1964) famous work on land rents and location in a monocentric city came out. Nowadays, thanks to advances in technology (e.g., GIS), the concept of location not only refers to the

S. K. Wong $(\bowtie) \cdot$ K. W. Chau · A. K. C. Cheung

Department of Real Estate and Construction, The University of Hong Kong,

Pokfulam Road, Pokfulam, Hong Kong

e-mail: skwongb@hku.hk

Y. Yau

Department of Public and Social Administration, City University of Hong Kong,

Tat Chee Avenue, Kowloon, Hong Kong 
distance of a property from the city centre, but is also extended to account for more complex spatial settings such as neighbourhood quality and accessibility to amenities. Many studies have examined location choice in relation to property value, socio-economic and demographic characteristics, and environmental factors (see, for example, Gabriel and Rosenthal 1989 and Gelfand et al. 2004).

This study extends previous research by examining empirically whether and how the price of a property varies with its vertical location and boundary. Most previous studies focused on the geographic (horizontal) dimension of location, while the vertical dimension of location has received much less attention. This inevitably limits our understanding of the value of high-rise living commonly seen in major cities around the world. Our study seeks to fill this knowledge gap by (1) examining the issues of transportation, environmental quality, and population density arising from high-rise living and (2) presenting comprehensive evidence on the pricing of two vertical property features through a carefully controlled experiment in Hong Kong.

The two vertical features that this study will empirically examine are floor level and building height. Floor level is the vertical distance between a housing unit and the ground level of a building, whereas building height represents the vertical distance between the roof and ground levels. These vertical features are key design parameters that developers have to carefully consider at the feasibility stage of a construction project. For instance, given a fixed development density (plot ratio), a developer needs to decide whether he should construct one super-tall tower or multiple blocks of shorter buildings. His decision would depend on the revenue and cost of different building designs, and property buyers' willingness-to-pay for vertical features is certainly a key determinant of the revenue.

The methodology of this study will be a hedonic price analysis of housing units located at different floor levels of apartment buildings. Before we present the empirical model, it is necessary to define two frequently used concepts that are central to this study. First, the floor-level premium refers to the extra price paid for higher vertical location (i.e., an upper floor level) of a housing unit. In a hedonic price framework, this is the marginal effect of a floor-level variable $(F L)$ on property prices $(P) .{ }^{1}$ The pattern of floor-level premiums along the vertical dimension of a building resembles Alonso's housing price gradient for a city. Second, a low-rise premium/discount is defined as the price paid for a housing unit in a shorter (low-rise) building compared to that for a taller (high-rise) building, with all other factors (including the floor level) being equal. In the next section, we shall introduce the hedonic price framework and discuss the pricing of floor level and building height in greater detail.

\section{Pricing of vertical location and building height}

Consider a very simple model of Ricardian rents in which a higher price is charged for land with locational advantages. Traditionally, as in Alonso's model, transportation cost is taken as the sole locational consideration so that land closer to a city's centre commands a higher price. To a certain extent, this is also true for housing units on lower floors, which have shorter "commuting" time to the building entrance and enjoy higher substitutability between staircases and lifts. These units, however, also suffer more from environmental problems, including air pollution, noise, lack of views, and security risk (Chau et al. 2004).

1 To be precise, this study defines property price as the price of a housing unit located on a particular floor of a multi-storey building. 
Fig. 1 Tradeoff between commuting time and environmental quality

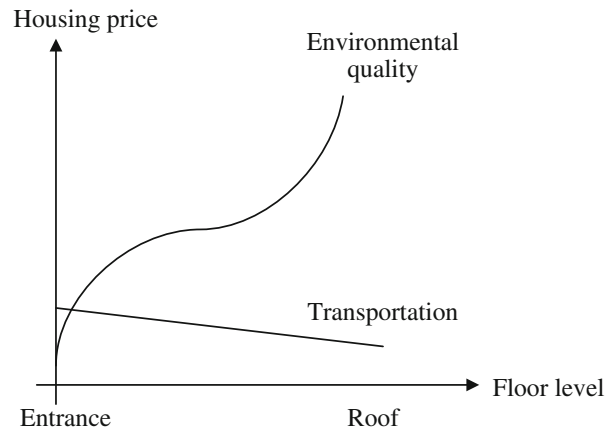

With the good and bad effects acting against each other, housing prices have to be adjusted to compensate for the net advantage of a vertical location. A graph discerning these two opposite effects is shown in Fig. 1. Since transportation cost (in terms of commuting time) is normally minimal in the presence of lift services, environmental quality tends to be the dominant effect. If this is the case, housing prices should rise with floor level, with all other factors being equal.

The price of vertical location can be estimated by adding a "floor" variable in a hedonic price model. Although floor level has seldom been the focus of hedonic price studies, it is routine to include "floor" in the hedonic price model for multi-storey buildings. ${ }^{2}$ Table 1 summarized the previous hedonic price studies that included "floor" as an independent variable. They unequivocally showed that the floor-level premium was positive (i.e., $\partial P /$ $\partial F L>0$ ), so housing units located on higher levels tend to command a premium. This observation appears to be universal across countries, including China, France, Hong Kong, Israel, Singapore, Switzerland, the UK, and the US. However, earlier researchers ignored the way in which the positive premiums varied with floor level and building height - they often treated one or more of the following assumptions as maintained hypotheses (without empirical tests) in their models:

(1) Linearity hypothesis: the floor-level premium is constant across different floor levels within the same building (or, more generally, buildings of the same height, $H$ ):

$$
\left.\frac{\partial P}{\partial F L}\right|_{F L=i ; H=m}=\left.\frac{\partial P}{\partial F L}\right|_{F L=j ; H=m} \quad \forall i \neq j
$$

(2) Absolute floor-level hypothesis: given the same floor level, the floor-level premium is constant across buildings with different heights:

$$
\left.\frac{\partial P}{\partial F L}\right|_{F L=i ; H=m}=\left.\frac{\partial P}{\partial F L}\right|_{F L=i ; H=n} \quad \forall m \neq n .
$$

There is, however, neither theoretical nor empirical justification for accepting these as maintained hypotheses. This study treats these as null hypotheses and empirically tests their validity. The first hypothesis may not hold because the marginal benefit of

2 Exceptions to this include Andersson (2000) and Lin and Hwang (2004), who ignored the floor effect in the hedonic modeling of multi-storey property prices. 
Table 1 A list of hedonic studies using "floor" as an independent variable

\begin{tabular}{|c|c|c|c|c|}
\hline Reference (year) & Location & $\begin{array}{l}\text { Specification of the floor } \\
\text { variable }\end{array}$ & $\begin{array}{l}\text { Floor-level } \\
\text { premium }\end{array}$ & $\begin{array}{l}\text { Range of floor } \\
\text { levels }\end{array}$ \\
\hline Wen et al. (2005) & Hangzhou, China & Linear & + & $>7$ \\
\hline $\begin{array}{l}\text { Gu and Colwell } \\
\text { (1997) }\end{array}$ & $\begin{array}{l}\text { Beijing and } \\
\text { Shenyang, China }\end{array}$ & Quadratic & + & $1-20$ \\
\hline $\begin{array}{l}\text { Meese and Wallace } \\
\text { (2003) }\end{array}$ & Paris, France & Linear & + & Not reported \\
\hline So et al. (1997) & Hong Kong & High/low zone dummies & + & Not reported \\
\hline Chau et al. (2001) & Hong Kong & Quadratic & + & $1-30$ \\
\hline $\begin{array}{l}\text { Borukhov et al. } \\
\text { (1978) }\end{array}$ & Israel & High/low zone dummies & + & Not reported \\
\hline Ong et al. (2003) & Singapore & Linear & + & $1-25$ \\
\hline Lum et al. (2004) & Singapore & Linear & + & $1-25$ \\
\hline $\begin{array}{l}\text { Baranzini and } \\
\text { Ramirez (2005) }\end{array}$ & $\begin{array}{l}\text { Geneva, } \\
\text { Switzerland }\end{array}$ & Linear & + & Not reported \\
\hline $\begin{array}{l}\text { Dunse and Jones } \\
\text { (1998) }\end{array}$ & Glasgow, UK & $\begin{array}{l}\text { Upper floors/ground floor/ } \\
\text { basement dummies }\end{array}$ & $\begin{array}{l}\text { Sign not } \\
\text { reported }\end{array}$ & Not reported \\
\hline Blomquist (1988) & Chicago, USA & Linear & + & Not reported \\
\hline
\end{tabular}

being located one floor higher is not necessarily fixed the higher one goes. ${ }^{3}$ As shown in Fig. 1, the floor-level premium represents the combined effect of transportation and environmental quality. Even if the marginal savings in transportation cost are constant, changes in environmental quality are likely to be non-linear. For instance, in avoiding street-level noise, the benefit of moving from the 10th to the 11th floor may be much smaller than that of moving from the 4th to the 5th floor due to diminishing marginal utility and/or the inverse square law governing sound transmission. We will therefore test whether floor-level premiums vary by floor. This is equivalent to testing if the land rent gradient is constant in a city when both transportation savings and environmental quality vary by location.

The second hypothesis is particularly interesting in the context of high-rise and low-rise buildings. It raises the question of whether the same floor-level premium is paid for highrise and low-rise buildings. For instance, given two otherwise identical buildings, do we pay the same floor-level premium for the 5th floor of a six-storey building and for that in a 36-storey building? "Of course" seems to be the intuitive answer, but the picture would be different if one considers the 5th floor a "high" floor in the six-storey building, but a "low" floor in the 36-storey one. In fact, when apartment units are marketed (e.g., advertised), it is common to emphasize the floor zone (e.g., low, mid, or high zone) rather than the exact floor level. Some previous studies also applied this logic in their hedonic price models. For instance, Anderson (2000) defined "relative floor" as the ratio of the actual floor level on which a property is located to the total number of storeys in the building. If the market values a "relative floor" rather than its absolute altitude, then one would expect to see different patterns of the floor-level premium in low-rise and high-rise buildings. This is the

\footnotetext{
${ }^{3}$ Some empirical studies reported non-linear price-floor-level relationships without further investigating the nature of the non-linearity. For example, Mason and Quigley (1996) showed that the price-floor-level relation was non-linear using data on condominium sales in downtown Los Angeles during the 1980s.
} 
second test we will perform. This is similar to testing if the rent gradients of different sized cities are the same. ${ }^{4}$

The third hypothesis that we will test is related to building height, which represents a building size when its footprint area is held constant. Building height is a feature of a building, not its constituent units, so it is not clear whether building height alone should affect the units' prices. Some studies incorporated the number of floors into their models (Gu and Colwell 1997; Baranzini and Ramirez 2005), but they often treated it as a trivial variable without further elaborating on the reasoning behind its use. For example, Gu and Colwell (1997) simply said, "people prefer low buildings [to] higher ones" (p. 136). Most other hedonic studies even ignored the effect of building height, thus assuming that (i.e., offered a constant density hypothesis):

$$
\frac{\partial P}{\partial H}=0
$$

Apparently, one could argue for a premium on high-rise buildings due to the prestige or reputation that their owners may enjoy. ${ }^{5}$ On the other hand, it can also be argued that there should be a discount on high-rise buildings because of the higher population densities they boast in common areas (assuming that they all have identical footprint areas). High density can have three undesirable effects. First, residents may feel overcrowded and stressed. A number of theoretical studies showed that places with higher population densities likely have a variety of negative effects on their residents, including physical, psychological, and social illnesses (Zlutnick and Altman 1972); stress and stress-related illnesses (Calhoun 1957); and crime and intergroup violence (Hartley 1972). Yet, empirical findings were mixed-some studies confirmed the negative effects (Galle et al. 1972; Tanaka et al. 1996), while others found a weak or even no association (Mitchell 1972; Schmitt et al. 1978; Millar 1979). Second, a high-density building reduces one's sense of privacy and tranquility. It is not unusual to see conflicts among residents over the sharing of communal facilities like staircases, corridors, lifts, and lobbies in condominium residences. Forced social interaction between non-relatives as a result of flat-sharing tends to create stress and tensions (Mitchell 1972). Third, the 2003 Severe Acute Respiratory Syndrome (SARS) outbreak further highlighted the dangers of living in a high living density environment because such a setting more easily facilitates the transmission of communicable diseases (Department of Health 2003; World Health Organization 2003). All these density effects suggest lower property prices for flats in high-rise buildings when compared to those in low-rise buildings (i.e., a low-rise premium), with all other things being equal. This is the third hypothesis that this study shall test.

The next section will outline how we will test the aforesaid hypotheses. We chose Hong Kong as the place for this empirical study in view of its high population density, abundance of multi-storey buildings, and active property market. With a total land area of $1,100 \mathrm{~km}^{2}$ and a present population of seven million, its overall population density is about 6,100 persons per $\mathrm{km}^{2}$. When considering urban areas alone, the population density is four times higher-about 26,000 persons per $\mathrm{km}^{2}$. To house so many people within the small land area, the government and private developers have built a large number of multi-storey

\footnotetext{
4 The monocentric city model asserts that the rent gradient is associated with transportation costs and density, not city size (DiPasquale and Wheaton 1996).

5 When comparing high- and low-rise buildings, one must bear in mind that other factors, including floor level, are held constant. It makes no sense to compare a unit on 50/F of a high-rise building with a unit on 10/F of a low-rise building.
} 
buildings. In 2004, the government estimated that there were around 42,000 private buildings territory-wide (Housing Planning and Lands Bureau 2004). Chau et al. (2005) provided statistics to show that Hong Kong's housing market, which is dominated by highrise residences, is one of the most actively transacted housing markets in the world. These competitive advantages make Hong Kong a highly favourable laboratory for gauging the effect of floor level and building height on property prices.

\section{Methodology}

Before carrying out our analysis, we need to provide a workable definition of the density of a building. We suppose that there are two building groups that are exactly the same except for their heights (i.e., one group is high-rise and the other is low-rise). Since they have the same number of flats and the same floor area on each storey, the taller building would have a higher population density in its common areas (e.g., a larger number of people sharing lift lobbies and communal facilities) than the shorter one. This means we can simply measure building density by building height. In the following sections, we will use the terms building density and building height interchangeably.

To evaluate how floor level and building height are priced, we applied hedonic price analysis, which has been frequently applied to study property prices (e.g., Leishman 2001; Song and Quercia 2008). According to Rosen's (1974) seminal work, hedonic price models can extract the implicit price of property attributes from property transaction prices. As such, they can be used to estimate the implicit prices of floor level and building height. But in the real world, buildings that vary by height usually have very different designs and location characteristics, rendering the separation of the implicit price of height from other design and location attributes difficult.

In Hong Kong, we were able to avoid the above collinearity problem by finding a housing estate (Telford Gardens) that has buildings with highly homogeneous attributes except for their heights (ranging from 11 to 26 storeys). Telford consists of 41 apartment building blocks with the same typical floor plan and building services systems. While the majority of the blocks are 11-12 storeys high (low-rise), there are 10 blocks that are 25-26 storeys high (high-rise). This unique housing development offers us a very good sample to study how property prices vary with floor level and building height.

For the sample, we collected the transaction data for housing units on or below the $10 / \mathrm{F}$ and excluded units on or above the $12 / \mathrm{F}$, as the transactions for units located on these floors were only available for the taller buildings. We also excluded flats on the 11/F because they are located just beneath the roof and are more prone to water leakage and noises, as well as vibrations generated by lifts. The quality of the top floor is therefore likely to be different from that of a lower floor. After eliminating non-usable transactions, a total of 807 transactions that took place from January 2000 to August 2006 remained in our sample.

Table 2 presents the descriptive statistics of the data. Transactions were reasonably distributed across the chosen range of floor levels $(1 / \mathrm{F}-10 / \mathrm{F})$, with an average of 5.33 and standard deviation of 2.84. In terms of building height, $75 \%$ of the transactions came from the low-rise buildings, a distribution that is consistent with the population (31 out of 41 blocks are low-rise). The majority (80\%) of purchases were single sales within the sample period, so selection bias due to repeat purchases should not be a major concern.

To estimate the implicit price of building density, we set a linear hedonic price model as follows: 
Table 2 Descriptive statistics of the property transaction data

\begin{tabular}{lrlll}
\hline & Mean & Std. dev. & Min & Max \\
\hline Telford Gardens (No. of transactions & 807) & & & \\
Property price (HK\$mil) & 1.66 & 0.34 & 0.95 & 2.69 \\
Age (year) & 22.08 & 1.96 & 18.00 & 26.08 \\
Flat size (ft ${ }^{2}$ ) & 601.42 & 30.98 & 392.00 & 681.00 \\
Floor level & 5.33 & 2.84 & 1.00 & 10.00 \\
MTR distance (m) & 155.45 & 55.87 & 64.35 & 231.23 \\
Street view (\%) & 0.17 & - & - & - \\
Podium garden view (\%) & 0.27 & - & - & - \\
MTR depot view (\%) & 0.13 & - & - & - \\
Low-rise building (\%) & 0.75 & - & - & - \\
\hline
\end{tabular}

$$
\begin{aligned}
P_{i t}= & \beta_{1} L R_{i}+\gamma_{1} F L_{i}+\gamma_{2} F L_{i}^{2}+\alpha_{0}+\alpha_{1} A G E_{i}+\alpha_{2} S_{I Z E_{i}+\alpha_{3} R D V_{i}} \\
& +\alpha_{4} G D V_{i}+\alpha_{5} D P V_{i}+\alpha_{6} M T R D_{i}+\alpha_{7} I N D E X_{i}+\varepsilon_{i t}
\end{aligned}
$$

The variables used in Eq. 4a are defined in Table 3. Variables like building age, flat size, views, distance to the MTR station, and time factors are control factors. ${ }^{6}$ Our first focus was on $\beta_{1}$, which measures the relative price of a low-rise building to a high-rise building (i.e., a test of Hypothesis 3). We expected its sign to be positive because, as discussed before, living in a dense environment may lead to overcrowding and higher mental and physical health risks. Our second interest lay in the coefficients of floor levels $\gamma_{1}$ and $\gamma_{2}$. We added a square term for floor level to cater for any non-linear effect (i.e., a test of Hypothesis 1). ${ }^{7}$ We expected $\gamma_{1}$ to be positive and $\gamma_{2}$ to be negative. We also estimated a more flexible specification for the price-floor relationship by replacing the continuous floor variable with floor dummies $F L(j)$ (see Table 3 for its definition) as the independent variables in the hedonic price model specification:

$$
\begin{aligned}
P_{i t}= & \beta_{1} L R_{i}+\sum_{j=2}^{10} \gamma_{j} F L(j)_{i}+\alpha_{0}+\alpha_{1} A G E_{i}+\alpha_{2} S I Z E_{i}+\alpha_{3} R D V_{i} \\
& +\alpha_{4} G D V_{i}+\alpha_{5} D P V_{i}+\alpha_{6} M_{T R} D_{i}+\alpha_{6} I N D E X_{i}+\varepsilon_{i t}
\end{aligned}
$$

The first floor is taken as the base floor level. As such, the coefficients of the floor dummies should be positive and increasing with floor level.

To test Hypothesis 2, we relaxed the assumption in Eq. 4a and $4 \mathrm{~b}$ that the patterns of the floor-level premium are the same for both low-rise and high-rise buildings. We added an interaction term for the low-rise dummy $(L R)$ and floor levels $(F L$ and $F L(j))$ to Eq. 4 a and 4b. The resulting equations were:

\footnotetext{
6 The base period for the time dummies was January 2000. The base view type for the view dummies is a building view.

7 We tried to add the square terms of $A G E$ and $S I Z E$ to the equation, but they were insignificant.
} 
Table 3 Definition of the variables

\begin{tabular}{ll}
\hline Variable & Definition \\
\hline$P_{i t}$ & The transaction price (in HK\$million) of property $i$ at time $t$ \\
$L R_{i}$ & A building height dummy that equals 1 when property $i$ is a low-rise and zero when it \\
is a high-rise & The floor level of property $i$ \\
$F L_{i}$ & A floor dummy that equals 1 when property $i$ is on the $j$ th floor and zero if otherwise (base \\
$F L(j)_{i}$ & floor $=1 / \mathrm{F})$ \\
$A G E_{i}$ & The building age of property $i$ in months \\
$S I Z E_{i}$ & The gross floor area of property $i$ in square feet \\
$R D V_{i}$ & A view dummy that equals 1 when property $i$ possesses a view facing the road and zero if \\
& otherwise \\
$G D V_{i}$ & A view dummy that equals 1 when property $i$ possesses a view facing the podium garden and \\
& zero if otherwise \\
$D P V_{i}$ & A view dummy that equals 1 when property $i$ possesses a view facing the MTR depot and zero \\
if otherwise
\end{tabular}

$$
\begin{aligned}
P_{i t}= & \beta_{1} L R_{i}+\beta_{2} L R_{i} \times F L_{i}+\beta_{3} L R_{i} \times F L_{i}^{2}+\gamma_{1} F L_{i}+\gamma_{2} F L_{i}^{2} \\
& +\alpha_{0}+\alpha_{1} A G E_{i}+\alpha_{2} S I Z E_{i}+\alpha_{3} R D V_{i}+\alpha_{4} G D V_{i} \\
& +\alpha_{5} D P V_{i}+\alpha_{6} M T R D_{i}+\alpha_{7} I N D E X_{i}+\varepsilon_{i t} \\
P_{i t}= & \beta_{1} L R_{i}+\sum_{j=2}^{10} \beta_{j} L R_{i} \times F L(j)_{i}+\sum_{j=2}^{10} \gamma_{j} F L(j)_{i}+\alpha_{0}+\alpha_{1} A G E_{i} \\
& +\alpha_{2} \operatorname{SIZE}_{i}+\alpha_{3} R D V_{i}+\alpha_{4} G D V_{i}+\alpha_{5} D P V_{i} \\
+ & \alpha_{6} \operatorname{MTRD}_{i}+\alpha_{7} I N D E X_{i}+\varepsilon_{i t} .
\end{aligned}
$$

If the coefficients of these interactive terms are significant, then that would imply different patterns of the floor-level premium. We shall present and discuss the results in the next section. The statistical software employed is EViews 6.

\section{Results}

The results of the two hedonic price models without interaction terms (i.e., Eq. $4 \mathrm{a}$ and $4 \mathrm{~b}$ ) are shown in Columns 1 and 2 of Table 4. The R-squared values of these models were over $85 \%$, indicating that our models explained a great deal of variability in the data. The two models were similarly structured except that Eq. 4a assumed a quadratic floor function and Eq. 4b a flexible step function. For both models, the coefficients of the control variables (except $A G E$ and $M T R D$ ) were highly significant with expected signs and comparable 
Table 4 Estimation results

\begin{tabular}{|c|c|c|c|c|}
\hline Variable & $\begin{array}{l}\text { Eq. } 4 \mathrm{a} \\
\text { Coefficient }\end{array}$ & $\begin{array}{l}\text { Eq. } 4 b \\
\text { Coefficient }\end{array}$ & $\begin{array}{l}\text { Eq. } 5 \mathrm{a} \\
\text { Coefficient }\end{array}$ & $\begin{array}{l}\text { Eq. } 5 \mathrm{~b} \\
\text { Coefficient }\end{array}$ \\
\hline$L R$ & $0.0486^{\mathrm{b}}$ & $0.0391^{\mathrm{b}}$ & $0.1092^{\mathrm{a}}$ & $0.1060^{\mathrm{b}}$ \\
\hline$F L$ & $0.1181^{\mathrm{b}}$ & - & $0.1280^{\mathrm{b}}$ & - \\
\hline$F L^{2}$ & $-0.0082^{\mathrm{b}}$ & - & $-0.0084^{\mathrm{b}}$ & - \\
\hline$F L(2)$ & - & $0.2460^{\mathrm{b}}$ & - & $0.2888^{\mathrm{b}}$ \\
\hline$F L(3)$ & - & $0.2966^{\mathrm{b}}$ & - & $0.3455^{\mathrm{b}}$ \\
\hline$F L(4)$ & - & $0.3214^{\mathrm{b}}$ & - & $0.4023^{\mathrm{b}}$ \\
\hline$F L(5)$ & - & $0.3345^{\mathrm{b}}$ & - & $0.3566^{\mathrm{b}}$ \\
\hline$F L(6)$ & - & $0.3490^{\mathrm{b}}$ & - & $0.4168^{\mathrm{b}}$ \\
\hline$F L(7)$ & - & $0.3739^{\mathrm{b}}$ & - & $0.3993^{\mathrm{b}}$ \\
\hline$F L(8)$ & - & $0.3691^{\mathrm{b}}$ & - & $0.4365^{\mathrm{b}}$ \\
\hline$F L(9)$ & - & $0.3662^{\mathrm{b}}$ & - & $0.4075^{\mathrm{b}}$ \\
\hline$F L(10)$ & - & $0.3611^{\mathrm{b}}$ & - & $0.4680^{\mathrm{b}}$ \\
\hline$L R^{*} F L$ & - & - & -0.0143 & - \\
\hline$L R^{*} F L^{2}$ & - & - & 0.0004 & - \\
\hline$L R * F L(2)$ & - & - & - & -0.0605 \\
\hline$L R^{*} F L(3)$ & - & - & - & -0.0684 \\
\hline$L R^{*} F L(4)$ & - & - & - & $-0.1117^{\mathrm{a}}$ \\
\hline$L R^{*} F L(5)$ & - & - & - & -0.0336 \\
\hline$L R * F L(6)$ & - & - & - & $-0.0983^{\mathrm{a}}$ \\
\hline$L R^{*} F L(7)$ & - & - & - & -0.0326 \\
\hline$L R^{*} F L(8)$ & - & - & - & -0.0903 \\
\hline$L R^{*} F L(9)$ & - & - & - & -0.0592 \\
\hline$L R^{*} F L(10)$ & - & - & - & $-0.1452^{\mathrm{b}}$ \\
\hline CONSTANT & $-2.4929^{\mathrm{b}}$ & $-2.3789^{\mathrm{b}}$ & $-2.520^{\mathrm{b}}$ & $-2.3945^{\mathrm{b}}$ \\
\hline$A G E$ & 0.0022 & 0.0017 & 0.0023 & -0.0017 \\
\hline SIZE & $0.0034^{\mathrm{b}}$ & $0.0033^{\mathrm{b}}$ & $0.0034^{\mathrm{b}}$ & $0.0033^{\mathrm{b}}$ \\
\hline$R D V$ & $-0.0935^{\mathrm{b}}$ & $-0.0997^{\mathrm{b}}$ & $-0.0966^{\mathrm{b}}$ & $-0.1059^{\mathrm{b}}$ \\
\hline$G D V$ & $0.0420^{\mathrm{b}}$ & $0.0470^{\mathrm{b}}$ & $0.0415^{\mathrm{b}}$ & $0.0436^{\mathrm{b}}$ \\
\hline$D P V$ & $-0.0817^{\mathrm{b}}$ & $-0.0839^{\mathrm{b}}$ & $-0.0816^{\mathrm{b}}$ & $-0.0810^{\mathrm{b}}$ \\
\hline$M T R D$ & $-2.68 \times 10^{-5}$ & $-9.96 \times 10^{-5}$ & $-2.13 \times 10^{-5}$ & $-8.35 \times 10^{-5}$ \\
\hline INDEX & $0.0198^{\mathrm{b}}$ & $0.0199^{\mathrm{b}}$ & $0.0198^{\mathrm{b}}$ & $0.0199^{\mathrm{b}}$ \\
\hline$R$-squared & 0.8520 & 0.8671 & 0.8532 & 0.8698 \\
\hline Adj. $R$-squared & 0.8501 & 0.8642 & 0.8510 & 0.8655 \\
\hline
\end{tabular}

We employed White's standard errors to adjust for heteroskedasticity

a Significant at the $5 \%$ level

b Significant at the $1 \%$ level

magnitudes. ${ }^{8}$ Most importantly, we found the following results regarding floor-level and low-rise premiums:

8 The insignificance of $A G E$ and $M T R D$ was probably due to low data variations. All buildings in the residential estate were built between 1980 and 1982 and were within $250 \mathrm{~m}$ of the subway station. 


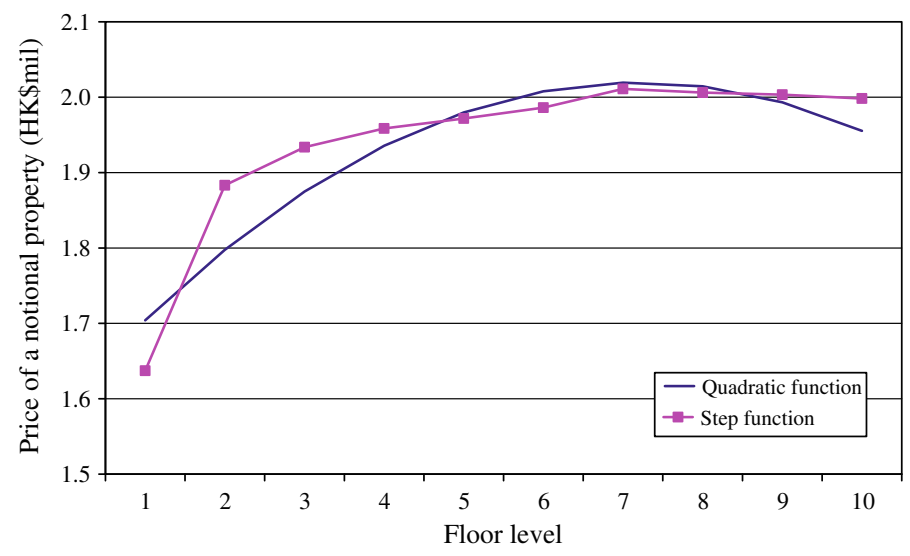

Fig. 2 The relationship between floor levels and property prices

Hypothesis 1 maintains that floor-level premiums are constant across different floor levels. However, in Eq. 4 a, both $\gamma_{1}$ and $\gamma_{2}$ were significant at the $1 \%$ level with opposite signs. This suggested that the floor-level premium diminishes as floor level increases, hence rejecting Hypothesis 1 . Since the quadratic floor function is rather restrictive, Eq. $4 \mathrm{~b}$ provided a flexible step function for estimating floor-level premiums. Both the results of the step and quadratic functions are plotted in Fig. 2. For the step function, we found a drastic jump in property prices from the 1 st to the 2 nd floor (about $15 \%$ of a property's price), which implied a great difference in perceived environmental quality (e.g., noise, security issues) between the first two floors. The premiums of the other floors appeared more or less the same, but a re-estimation of Eq. 4a without the first floor still showed a slightly diminishing pattern (with $\gamma_{1}=0.0505$ and $\gamma_{2}=-0.0031$, both significant at the $1 \%$ level). Therefore, the hypothesis that the floor price gradient is linear was rejected as far as the low floor zone was concerned. A non-linear gradient likely resulted from variations in environmental quality along the vertical dimension.

Hypothesis 3 maintains that low-rise buildings do not command a premium or discount over high-rise buildings. However, in both Eq. $4 \mathrm{a}$ and $4 \mathrm{~b}$, the low-rise premium $\left(\beta_{1}\right)$ was consistently positive and significant at the $1 \%$ level, suggesting that units in taller (and thus, denser) buildings were sold at a discount to units in shorter buildings, ceteris paribus. The estimated low-rise premiums were HK\$48,584 in Eq. 4a and HK\$39,076 in Eq. 4b, representing about $2-3 \%$ of the mean transaction price in the sample. These results rejected the constant density hypothesis and confirmed that there was a greater premium for shorter buildings than for taller ones. The premium can be attributed to a lower population density in the common areas of shorter buildings, as elaborated on in Sect. 2.

Next, we estimated Eq. $5 \mathrm{a}$ and $5 \mathrm{~b}$ to test if the pattern of the floor-level premiums was constant across buildings of different heights, as maintained by Hypothesis 2. The regression results of Eq. 5a and 5b are shown in Columns 3 and 4 of Table 4. Central to these equations are the interaction of terms $L R$ with the floor levels. Both interaction terms in Eq. $5 \mathrm{a}$ and most of the interaction terms in Eq. 5b, however, were insignificant. There was no evidence to support the "relative" logic that floor-level premiums varied with buildings of different heights. Hence, Hypothesis 2 was not rejected. 
Last but not least, as in Eq. 4a, Hypothesis 1 was rejected again in Eq. 5a in favour of the existence of the diminishing floor premium. Similarly, Eq. 5a and 5b affirmed the rejection of Hypothesis 3 in favour of a low-rise premium. The coefficients of the other control variables were largely the same as before. This shows the robustness of our results across different specifications. ${ }^{9}$

\section{Conclusion}

Based on two highly homogeneous groups of low-rise and high-rise buildings, we evaluated three hypotheses on the relationship between housing prices and floor levels in Hong Kong based on the hedonic price analysis. First, we found that the floor-level premium was not constant, but diminished with respect to rising floor levels in all hedonic model specifications. Second, although high-rise, high-density living is the norm in Hong Kong, the results consistently suggested that people still preferred to live in low-rise, and hence, less densely populated, buildings. Third, there was no significant difference in the pattern of floor-level premiums between high-rise and low-rise buildings, so the notion that the market values relative floor levels rather than absolute levels was not supported.

One obvious implication of the results is the specification of the hedonic price model for multi-storey residential buildings. In the literature, there were generally two ways to handle floor premiums in the hedonic price model: (1) high/low zone dummies and (2) linear specification (see Table 1). However, these methods are too restrictive to cope with changing environmental quality along the vertical dimension. Our results demonstrated that the floor price gradient is not linear in our case, so we would prefer more flexible specification on the floor-level premium. Moreover, we showed that the height of a building (as measured by total number of storeys) matters in pricing properties. Future hedonic studies should take this important, yet frequently ignored, factor into account.

Another implication is that developers can build taller residential buildings to boost revenue, although the marginal benefit of building an additional floor must be balanced against its cost. Based on the evidence we submitted above, there are two important considerations for determining a building's height. First, contrary to conventional thought, the floor-level premium is not constant. Our results suggested that it actually diminished as floor level increases, as far as a low floor zone is concerned. Second, due to congestion, there was an adverse density effect on the property values of taller buildings with the same footprint area. These two considerations, together with information on construction costs and regulatory constraints, should be taken into account when determining the optimal height of a building. Interested readers may refer to Chau et al. (2007), which found that observed building height is very close to the theoretical optimal level derived from relevant cost and benefit constraints.

Open Access This article is distributed under the terms of the Creative Commons Attribution Noncommercial License which permits any noncommercial use, distribution, and reproduction in any medium, provided the original author(s) and source are credited.

\footnotetext{
9 A further robustness check was conducted by a fixed effect model in which a dummy for each separate building was added to Eqs. $4 \mathrm{a}$ and 5a. Hypothesis 1 was again rejected, with similar coefficients on $F L$ (0.1169) and $F L^{2}(-0.0081)$ as before. The coefficients on $L R^{*} F L$ and $L R^{*} F L^{2}$ were insignificant, hence failing to reject Hypothesis 2 as before. Hypothesis 3 cannot be tested in the fixed effect model because $L R$ is exactly collinear with the building-specific dummies.
} 


\section{References}

Alonso, W. (1964). Location and land use. Cambridge: Harvard University Press.

Anderson, J. E. (2000). Housing privatization in transition economies. Retrieved 20 Dec 2006, from SSRN Web site: http://ssrn.com/abstract=253767.

Andersson, D. E. (2000). Hypothesis testing in hedonic price estimation-on the selection of independent variables. The Annals of Regional Science, 34(2), 293-340.

Baranzini, A., \& Ramirez, J. V. (2005). Paying for quietness: The impact of noise on Geneva rents. Urban Studies, 42(4), 633-646.

Blomquist, G. (1988). Valuing urban lakeview amenities using implicit and contingent markets. Urban Studies, 25, 333-340.

Borukhov, E., Ginsberg, Y., \& Werczberger, E. (1978). Housing prices and housing preferences in Israel. Urban Studies, 15, 187-200.

Calhoun, J. B. (1957). Social welfare as a variable in population dynamics. Cold Spring Harbor Symposia on Quantitative Biology, 22, 339-356.

Chau, K. W., Ma, V. S. M., \& Ho, D. C. W. (2001). The pricing of "luckiness" in the apartment market. Journal of Real Estate Literature, 9(1), 31-40.

Chau, K. W., Wong, S. K., Yau, Y., \& Cheung, A. K. C. (2007). Determining optimal building height. Urban Studies, 44(3), 591-607.

Chau, K. W., Wong, S. K., \& Yiu, C. Y. (2004). The value of the provision of a balcony in apartments in Hong Kong. Property Management, 22(3), 250-264.

Chau, K. W., Wong, S. K., Yiu, C. Y., \& Leung, H. F. (2005). Real estate price indices in Hong Kong. Journal of Real Estate Literature, 13, 337-356.

Department of Health. (2003). Main findings of an investigation into the outbreak of SARS at Amoy Gardens. Retrieved 19 Nov 2004, from Hong Kong Government Web site: http://www.info.gov.hk/info/ap/.

DiPasquale, D., \& Wheaton, W. C. (1996). Urban economics and real estate markets. N.J.: Prentice-Hall.

Dunse, N., \& Jones, C. (1998). A hedonic price model of office rents. Journal of Property Valuation \& Investment, 16(3), 297-312.

Gabriel, S. A., \& Rosenthal, S. S. (1989). Household location and race: Estimates of multinomial logit model. Review of Economics \& Statistics, 71(2), 240-249.

Galle, O. R., Gove, W. R., \& McPherson, J. M. (1972). Population density and pathology: What are the relations for man? Science, 176(30), 23-30.

Gelfand, A. E., Ecker, M. D., Knight, J. R., \& Sirmans, C. F. (2004). The dynamics of location in home price. Journal of Real Estate Finance and Economics, 29(2), 149-166.

Gu, Y. A., \& Colwell, P. F. (1997). Housing rent and occupational rank in Beijing and Shenyang, People's Republic of China. Journal of Property Research, 14, 133-143.

Hartley, S. F. (1972). Population: Quantity vs. quality: A sociological examination of the causes and consequences of the population explosion. Englewood Cliffs, N.J.: Prentice-Hall.

Housing Planning and Lands Bureau. (2004). Building management and maintenance-consultation paper. Hong Kong: Government Logistics Department.

Leishman, C. (2001). House building and product differentiation: An hedonic price approach. Journal of Housing and the Built Environment, 16, 131-152.

Lin, J. J., \& Hwang, C. H. (2004). Analysis of property prices before and after the opening of the Taipei subway system. The Annals of Regional Science, 38(4), 687-704.

Lum, S. K., Koh, T., \& Ong, S. E. (2004). Upgrading programme in public housing: An assessment of price and liquidity enhancements. Journal of Property Research, 21(2), 143-159.

Mason, C., \& Quigley, J. M. (1996). Non-parametric hedonic housing prices. Housing Studies, 11(3), 373-386.

Meese, R., \& Wallace, N. (2003). House price dynamics and market fundamentals: The Parisian housing market. Urban Studies, 40(5-6), 1027-1045.

Millar, S. E. (1979). The biosocial survey in Hong Kong. Canberra: Central Printery, Australian National University.

Mitchell, R. E. (1972). Levels of emotional strain in Southeast Asian cities: A study of individual responses to the stresses of urbanization and industrialization. Taipei: Orient Cultural Service.

Ong, S. E., Ho, K. H. D., \& Lim, C. H. (2003). A constant-quality price index for resale public housing flats in Singapore. Urban Studies, 40(13), 2705-2729.

Rosen, S. (1974). Hedonic prices and implicit markets: Product differentiation in pure competition. The Journal of Political Economy, 82(1), 34-55.

Schmitt, R. C., Zane, L. Y., \& Nishi, S. (1978). Density, health, and social disorganization revisited. Journal of American Institute of Planners, 44(2), 209-211. 
So, H. M., Tse, R. Y. C., \& Ganesan, S. (1997). Estimating the influence of transport on house prices: Evidence from Hong Kong. Journal of Property Valuation \& Investment, 15(1), 40-47.

Song, Y., \& Quercia, R. G. (2008). How are neighbourhood design features valued across different neighbourhood types? Journal of Housing and the Built Environment, 23(4), 297-316.

Tanaka, A., Takano, T., Nakamura, K., \& Etkeuchi, S. (1996). Health levels influenced by urban residential conditions in a megacity-Tokyo. Urban Studies, 33(6), 879-894.

Wen, H. Z., Jia, S. H., \& Guo, Z. Y. (2005). Hedonic price analysis of urban housing, an empirical research on Hangzhou, China. Journal of Zhejiang University Science, 6A(8), 907-914.

World Health Organization. (2003). Final report-Amoy Gardens-WHO environmental investigation. Retrieved Nov 20 Nov 2004, from the IAPMO Web site: http://www.iapmo.org.

Zlutnick, S., \& Altman, I. (1972). Crowding and human behaviour. In J. F. Wohlwill \& D. H. Carson (Eds.), Environment and the social sciences. Washington, D.C.: American Psychological Association. 